\title{
INCENTIVOS AOS INVESTIMENTOS AMERICANOS NO BRASIL
}

\begin{abstract}
Para o investidor norte-americano no Brasil, as impressões subjetivas dos mais importantes executivos sôbre a situação política e econômica do país são fatôres de decisão mais essenciais do que quaisquer cálculos normais de negócios.
\end{abstract}

A decisão de investir no próprio país e investir em terras estrangeiras envolve processos totalmente diversos. Esta é, em sintese, uma das principais conclusões de um inquérito realizado entre executivos norte-americanos cujas companhias mantêm emprêsas filiadas no Brasil.

Êste artigo descreve, em têrmos gerais, de que maneira êsses processos diferem, com referência especial ao ambiente econômico brasileiro no período do após-guerra.

\section{Natureza e Escopo do Inquérito}

Inicialmente, talvez seja apropriado fazer breve comentário sôbre o estudo em si.

Sob os auspícios do "Centro de Negócios Internacionais" da "Universidade de Harvard" e com o auxílio financeiro da "Ford Foundation", iniciou-se, há dois anos, um estudo refe-

LINCOLN GORDON - Professor de Relações Econômicas Intermacionais («International Economic Relations») da «Harvard Business School».

Nota do Autor: O presente artigo foi escrito antes de êste autor ter sido nomeado, em agôsto de 1961, Embaixador dos Estados Unidos da América no Brasil; não conta com patrocínio oficial, não devendo as opiniōes nêle contidas serem consideradas como reflexo da política. do Govêrno Americano. 
rente à atuação e relações entre govêrno e comunidade de negócios brasileiros no desenvolvimento econômico do Brasil. Este projeto faz parte de um amplo programa de pesquisas que investiga problemas similares num grupo de países em fase de desenvolvimento, em diversas partes do mundo.

O objetivo será identificar a atuação do govêrno e das emprêsas na promoção do desenvolvimento econômico, suas respectivas contribuições à formação de capital e a transformações na estrutura econômica e, em especial, as relações entre os setores público e privado. O programa também trata das atitudes históricas e contemporâneas em relação à emprêsa e às fontes empresariais, fazendo uma minuciosa verificação das diretrizes governamentais que têm afetado, favorável ou adversamente, o desenvolvimento econômico. $O$ período histórico a ser analisado compreende os últimos trinta anos, com ênfase especial na fase posterior à Segunda Grande Guerra.

O projeto brasileiro foi dirigido por êste autor. A parcela principal do trabalho foi realizada no Brasil, em cooperação .com especialistas brasileiros em vários aspectos do deservolvimento econômico. Uma das fases do estudo compreenderá um levantamento da experiência das emprêsas brasileiras com relação a diretrizes de governos diversos e está sendo realizada por um grupo de pesquisadores que pertencem ao corpo docente da "Escola de Administração de Emprêsas de São Paulo".

Em vista da participação substancial de emprêsas particulares norte-americanas no desenvolvimento brasileiro durante o período do após-guerra, decidiu-se realizar um inquérito especial, nos Estados Unidos, entre companhias americanas com importantes subsidiárias ou afiliadas operando no Brasil.

Os dados básicos dêsse inquérito foram colhidos no período de setembro de 1960 a maio de 1961, em longas entrevistas com executivos e assessôres especializados de departamentos ou divisões internacionais de trinta e seis emprêsas industriais norte-americanas. A maior parte das entrevistas, que tiveram duração média de duas a três horas, foi realizada pelo SR. ENGELBERT CROMMERS, pesquisador da "Harvard Business 
School", tendo êste autor também participado de grande número delas.

As entrevistas basearam-se num esbôço de 17 páginas que continha: objetivo da entrevista, tópicos a serem cobertos e dados informativos sôbre os tópicos sempre que necessário.

As entrevistas não se limitavam aos tópicos constantes da relação contida no esbôço. No decorrer do projeto de pesquisa, foram identificadas novas áreas de problemas. A flexibilidade do método de entrevistas orais possibilitou, em cada caso, uma concentração nas emprêsas com experiências que apresentavam maior relevância para o projeto.

Os principais resultados dêsse inquérito serão publicados brevemente nos Estados Unidos. Neste artigo, restringir-nos-emos a algumas generalizações resultantes da experiência de todo o grupo de companhias participantes, analisando primeiramente os principais elementos que motivaram as decisões referentes a investimentos, para, em seguida, fazer uma apreciação sintetizada sôbre o ambiente existente no Brasil de após-guerra para as emprêsas industriais estrangeiras, através dos olhos dos executivos entrevistados.

\section{O Incentivo das Posições Estabelecidas}

Mais importante que qualquer obstáculo ou incentivo às opeções industriais tem sido a conviç̧ão generalizada, entre as companhias participantes, de que o Brasil apresenta um mercado vasto, com potencial para um rápido crescimento e que, em têrmos gerais, oferece um bom ambiente para a emprêsa industrial estrangeira. Esstes aspectos poderiam ser considerados como condições prévias ao funcionamento das medidas específicas de incentivo.

Na qualidade de país de enormes dimensões, com uma população em rápido crescimento, o Brasil atrai, quase automàticamente, a atenção das companhias que dedicam algum pensamento a investimentos estrangeiros em regiões que não as altamente avançadas do globo. Mesmo que, segundo dis- 
se um administrador, a metade ou mais da população não possa ser considerada como consumidora potencial de produtos manufaturados, o Brasil, ainda assim, representa uma das mais importantes áreas de mercado dentre os países subdesenvolvidos.

Além do tamanho, o Brasil do após-guerra tem apresentado a atração adicional do crescimento econômico quase contínuo, que contrabalança fatôres desencorajantes como a inflação crônica, os complexos contrôles sôbre câmbio e importações e certos aspectos da legislação trabalhista e fiscal.

Além disso, a área altamente dinâmica de rápido crescimento industrial com base em São Paulo, mas estendendo-se, até certo grau, a tôda a região sul e centro-sul do país, tem sido importante foco de atração, oferecendo muitas das "economias externas" que facilitam o caminho do industrial pioneiro. Finalmente, durante todo o periodo do após-guerra, o investimento industrial estrangeiro no mercado doméstico tem sido bem recebido, tanto pelo govêrno quanto pela comunidade brasileira de negócios.

Dadas essas condições básicas, é claro que o incentivo específico mais poderoso ao investimento industrial tem sido a "lei de similares". Por meio de medidas legais de uma ou outra forma, esta tem dado proteção substancial àqueles que decidem dedicar-se a fabricação ativa, além de ameaçar de completa exclusão do mercado a companhia retardatária.

Esse incentivo tem produzido maior efeito nos casos de emprêsas que já fazem exportações substanciais para o Brasil, ou que montam produtos finais com materiais e componentes importados. Em geral, a preservação de uma posição comercial estabelecida parece ser um motivo mais poderoso para investir em estabelecimentos industriais no estrangeiro do que cálculos cuidadosos sôbre a possível lucratividade a curto prazo.

Quanto maiores os investimentos prévios em acomodações para distribuição ou montagem, tanto mais sensível será a 
companhia a tais incentivos. Dadas as condições básicas acima descritas, a política mais eficiente para uma nação sub. desenvolvida à procura de investimentos industriais estrangeiros pareceria ser, portanto, a substituição progressiva das importações pela montagem e da montagem por fabricação doméstica mais completa.

No primeiro estágio, o desejo da companhia de manter seu mercado anterior de exportação quase certamente supera os investimentos relativamente pouco importantes que são exigidos. Defrontando-se, mais tarde, com a escolha entre fabricar ou abandonar a posição comercial e o investimento em acomodações de montagem, a companhia estrangeira sentir-se-á mais inclinada a iniciar a fabricação do que se tivesse apenas ativos intangíveis a proteger. Além disso, em muitos casos, é mais fácil persuadir uma companhia a financiar a fabricação com lucros retidos de operações de montagem do que a empregar fundos substanciais da emprêsa matriz.

Portanto, o principal motivo para entrar nas atividades de produção no estrangeiro é o desejo de alcançar ou manter um ponto de apoio num mercado de modo geral atraente, quando as diretrizes governamentais não deixam outro meio de atingir êste objetivo a não ser o do investimento direto. Comparado com êste poderoso incentivo, medidas tais como reduções de impostos ou tratamento preferencial de tarifas e câmbio para equipamento e componentes parecem ser de importância apenas secundária.

\section{Aspectos Legais e o "Efeito de Choque"}

A proteção contra a concorrência da importação é, naturalmente, parte do incentivo principal. As outras medidas são apenas suplementares. No caso brasileiro, as reduções de impostos são usadas apenas em regiões limitadas ou no nível municipal. Sem dúvida, a mais importante medida tomada no após-guerra para atrair os investidores industriais estrangeiros, em geral, foi a "Instrução 113" da "SUMOC". E significativo que quase tôdas as companhias participantes de nosso estudo tenham obtido benefícios com a Instrução 113 ; tôdas as que o fizeram sentiam-se satisfeitas por terem 
aproveitado suas vantagens; mas nenhuma delas considerava êsse benefício como um fator crucial na sua decisão de investir.

Ao mesmo tempo, as medidas dêste tipo podem ter importante efeito psicológico, despertando a atenção das companhias para as possibilidades de investimento no estrangeiro, ou precipitando uma decisão sôbre diretrizes àrduamente debatida num conselho diretor ou entre executivos de alto nível. Dado o caráter subjetivo de muitas das decisões sôbre investimento estrangeiro, êsse efeito "propagandístico" ou "de choque" pode apresentar importância muito maior do que nos negócios internos. Acreditamos que, em alguns casos, tenha sido precisamente êsse o efeito da Instrução 113.

Um efeito "de choque" semelhante pode ser produzido por outras fontes. Assim, por exemplo, o boato de que um concorrente está planejando um investimento industrial no qual será protegido pela "lei de similares" torna-se um "estopim" generalizado para uma decisão favorável sôbre investimento no estrangeiro. Às vêzes, a iniciativa pode partir de homens de negócios brasileiros, proprietários de fábricas relativamente pequenas, que carecem de recursos para pesquisa e desenvolvimento e vêm aos Estados Unidos à procura de parceiros para suprir sua tecnologia e suplementar seus recursos de capital. Diversas companhias participantes foram abordadas dessa maneira e, muito prontamente, tendiam a entrar em aventuras conjuntas sob tais condições. Êste foi especialmente o caso da indústria química. Em sua forma típica, o investimento inicial consistia principalmente de assistência técnica, reembolsável pelo pagamento de taxas e "royalties", envolvendo apenas um diminuto compromisso financeiro. Uma vez estabelecido dêsse modo, os subseqüentes programas de expansão, envolvendo maiores aplicações de capital, eram baseados em cálculos mais objetivos. Nessa fase, as companhias levavam cuidadosamente em conta a política governamental de câmbio e contrôle de importação.

Tôdas essas formas de incentivo são reforçadas pelo efeito do exemplo, mormente quando êle é dado pelas companhias. de maior renome. A moda constitui importante fator nos. 
investimentos estrangeiros, assim como em outros campos. de decisão humana e pode-se observar que os investimentosestrangeiros, no Brasil, nos últimos anos da década de 50, demonstram inequívoca tendência de seguir caminhos já traçados.

Todos êsses fatôres operam dentro da moldura geral a que se chama de "clima de investimento" - a reputação geral de que goza um país entre investidores estrangeiros atuais e em potencial. É claro que as medidas de contrôle ou os incentivos têm certa influência sôbre esta reputação geral. Ela demonstrou perceptível melhoria no Brasil, em 1953, por exemplo, quando foram removidas as limitações sôbre remessas de dividendos, ainda que a taxa de câmbio para essas remessas tenha-se tornado menos favorável. Nesse ano, a instituição do mercado de leilão para o câmbio estrangeiro destinado à importação, em lugar do sistema de licenças de importação, altamente burocrático, teve um efeito semelhante. Mais significativa, ainda, tem sido a ausência generalizada de discriminação contra investidores estrangeiros, simbolizada de modo positivo pela Instrução 113 .

\section{Promoção Industrial Especial}

Nos casos em que o govêrno estabeleceu metas de investimento específicas para um número limitado de indústrias, a experiência brasileira indica que um programa de benefícios para investidores estrangeiros, administrado por uma agência executiva que goze de bastante liberdade de negociação e somado a punições para os não-participantes, pode obter um sucesso excepcional. A criação de uma indústria completa de produção de veículos e peças para automóveis em menos de cinco anos é o exemplo mais evidente disto.

Neste caso em particular, o nível geral de desenvolvimento econômico ainda não atingira o ponto em que o investimento privado pudesse ser atraído, na escala desejada, pelo simples. funcionamento das "leis de similares" e pelo tratamento favorável de importação de maquinaria. É particularmente significativo que, através da técnica de tornar os fabricantes de 
veículos responsáveis pela nacionalização do conteúdo de seus produtos durante um período relativamente curto, foi criada uma grande indústria de suprimento de peças sem a necessidade de uma intervenção direta do govêrno em moldes extensos.

E discutível que técnicas semelhantes poderiam ser aplicadas a um grande número de indústrias sem interferência mútua por parte das agências promotoras e uma diluição da estrutura de incentivos. Todavia, na forma em que foi aplicado a pontos críticos de "engarrafamento" e "pontos de crescimento" econômico, êsse método de estimular o investimento privado na expansão industrial parece ter evidenciado méritos.

\section{Diretrizes que Dificultam o Crescimento Industrial}

As diretrizes governamentais brasileiras tanto têm colocado incentivos como obstáculos aos investimentos industriais. Ainda que, segundo parece, poucas tenham sido as indústrias amedrontadas por êsses obstáculos, pode-se supor que, num país que oferecesse um mercado menos atraente, semelhantes diretrizes e condições teriam um efeito negativo muito maior.

De modo geral, a inflação crônica não tem desencorajado, por si, as companhias participantes de realizarem investimentos adicionais, seja na expansão de acomodações existentes, seja em novas linhas de negócios. Todavia, entre os produtos correlatos da inflação, incluem-se sérios problemas financeiros resultantes da carência de créditos a curto prazo e de capital a longo prazo. Algumas companhias têm abandonado determinadas linhas de negócios, por não desejarem assumir a carga do financiamento a intermediários e consumidores. A fraqueza do mercado de capital tem impedido outros investidores de usar emissões de ações para obter a participação do público brasileiro em suas companhias. As principais dificuldades surgidas no campo fiscal são, também, resultado indireto do ambiente inflacionário.

A inadequação dos serviços públicos de comunicações, transporte e, especialmente, de energia elétrica tem sido outra 
fonte de dificuldades para as indústrias estrangeiras. Ela tem, por vêzes, levado os investidores a montar ineficientes substitutos particulares e, em geral, tem aumentado de modo substancial os custos de operação.

As deficiências na estrutura educacional também têm dificultado a obtenção de pessoal de nível administrativo médio e exigido das emprêsas o estabelecimento de programas especiais para treinamento de operários e funcionários de escritório. As complexidades e irregularidades administrativas, bem como as mudanças freqüentes de diretrizes regulamentares são objeto de queixas generalizadas por parte dos investidores estrangeiros. Isto acontece em particular no terreno do contrôle da importação, do câmbio e do crédito. A situação é exemplificada pelo comentário que o executivo de uma companhia fêz a respeito de seus colegas brasileiros: disse êle que os mesmos tinham de gastar tempo excessivo estudando regulamentações e negociando com os funcionários do govêrno, em vez de cuidar das diretrizes de produção e vendas e de administrar as operações das emprêsas. A simplificação gradual da maioria dêsses contrôles durante o período estudado e a substituição dos métodos baseados em discriminação administrativa por técnicas mais objetivas foram fatôres importantes para encorajar o maior fluxo de novos investimentos.

\section{O Clima de Investimentos no Brasil}

A despeito das dificuldades acima resumidas, as reações finais dos executivos entrevistados foram uniformemente favoráveis ao Brasil, como nação em que estrangeiros podem desenvolver operações industriais. Perguntou-se-lhes : - "Se você pudesse tomar novamente sua decisão sôbre investimentos, à luz do que agora sabe teria feito algo muito diferente?" Em têrmos gerais, responderam os entrevistados que quase tudo dera certo e que os erros de julgamento tinham sido limitados a pormenores. Os erros mais comuns foram cometidos em relação a estimativas deficientes da capacidade produtiva necessária, ou quanto aos tipos de produtos que seriam mais procurados. Em muitos casos, tais erros foram atribuídos à inexistência de dados mercadológicos apropria- 
dos. Mesmo quando era possível obter dados estatístico-históricos, o ritmo do crescimento econômico, somado ao caráter variante da demanda e às incertezas resultantes da inflação, dificultou a projeção de tendências futuras. Companhias que agiram sob o efeito da "lei de similares" ou sob outros efeitos "de choque", em regra, não tinham tido tempo para uma pesquisa cuidadosa sôbre o potencial de mercado.

Todavia, nos casos em que tinha sido criada uma supercapacidade inicial, ela foi, em geral, absorvida prontamente, devido ao rápido crescimento das vendas. De modo geral, foi também possível modificar os tipos de produtos sem despesas excessivas. Só uma companhia participante considera ter cometido sério êrro nesse particular. Em alguns casos, o potencial de mercado foi subestimado e as companhias lamentaram que seus investimentos iniciais não tenham sido maiores. Uma das companhias, depois de poucos anos de operação, desejava substituir parte de sua maquinaria original por equipamento mais automatizado e de maior velocidade.

O consenso dos executivos foi altamente otimista, com relação ao futuro desenvolvimento da economia brasileira. As oportunidades para mais amplos investimentos na produção foram consideradas como sendo grandes e as atitudes oficiais e populares em relação a emprêsas estrangeiras foram tidas como mais favoráveis do que na maioria dos países em desenvolvimento.

Todavia, demonstrou-se certa preocupação ante a continuada inflação, baseada no fato de que poderia solapar a estabilidade social e política da nação. Havia também um receio de que medidas anti-inflacionárias pudessem tomar a forma de contração nos investimentos produtivos.

Em verdade, as incertezas causadas pela inflação foram a principal nota de cautela, dentro do otimismo geral. Um executivo deu, nos seguintes têrmos, uma ampla visão da situação : "Eu diria que o futuro do Brasil poderia ser brilhante, mas às vêzes fico um tanto preocupado com a fé que os brasileiros depositam na idéia de que êsse futuro brilhante virá au- 
tomática e inevitàvelmente. A prevalência de tal filosofia tem, talvez, causado um obscurecimento na perspectiva dos brasileiros quanto às responsabilidades que deveriam ser enfrentadas de imediato".

Entre as experiências obtidas nos países subdesenvolvidos, a brasileira foi, geralmente, tida como insòlitamente satisfatória. Por outro lado, verificou-se que ela apresentava problemas administrativos maiores do que no Canadá ou na Europa Ocidental. Uma companhia com emprêsas afiliadas em tôdas as partes do mundo expressou um ponto de vista que obteve amplo assentimento por parte das demais : "Nosso negócio brasileiro implica em grandes dificuldades de tôdas as espécies - produção, finanças, vendas, pessoal administrativo e negociações governamentais -; contudo, estamos felizes de ali nos encontrarmos, jamais pensaríamos em nos afastar e esperamos contínuo crescimento e sucesso".

\section{Conclusões}

Há muito se reconhece que o investimento em indústrias manufatureiras depende de um número limitado de importantes decisões por parte de uma quantidade relativamente pequena de emprêsas.

Isto, contudo, não significa que 0 investidor potencial em indústrias de fabricação seja indiferente às fôrças de mercado. Teòricamente, êle toma a decisão de investir baseado em cálculus racionais, começando com pesquisas científicas de mercado e previsões de volume potencial de vendas, custos e preços. Êle considera, comumente, também as possíveis e prováveis reações dos competidores e, então, tenta "maximizar" os retornos, na base de cálculos de "valor presente" dos lucros esperados no futuro.

Embora ninguém afirme que tôdas as decisões domésticas sôbre investimentos sigam esta ordenação racional em todos seus pormenores, as companhias bem administradas certamente se aproximam dêste ideal. As companhias bem administradas são usualmente as mais bem sucedidas e, frequientemente, as que mantêm as vistas voltadas para as possibili- 
dades dos mercados estrangeiros. Poder-se-ia, portanto, esperar que as decisõei aplicadas no mercado doméstico seriam as miesmas usadas para a expansão internacional.

Na prática, entretanto, êsse não é geralmente o caso das companhias norte-americanas que operam nas nações subdesenvolvidas. O mesmo ideal de cálculos racionais pode ser desejado, mas, na maioria das áreas, não há dados para pesquisas sistemáticas de mercado, a experiência histórica que poderia servir de guia é reduzida e as diretrizes governamentais e atitudes políticas têm uma consequiência maior sôbre as perspectivas de sucesso ou fracasso.

Como resultado, o processo real de decisão é mais subjetivo. dependendo das impressões dos principais executivos quan. to à provável feição do mercado para o produto em questão e à evolução do ambiente político e econômico.

Este aspecto saltou bastante à vista nas entrevistas em que nosso estudo foi baseado. Ele talvez contenha algumas implicações significativas para brasileiros e americanos interessados em estimular os investimentos estrangeiros no Brasil. 